AGH DRILLING, OIL, GAS • Vol. 32 • No. 2 • 2015

http://dx.doi.org/10.7494/drill.2015.32.2.325

\author{
Oleksandr Kondrat*
}

\title{
INVESTIGATION \\ OF THE INTERACTION OF RESERVOIR SECTIONS WITH DIFFERENT PERMEABILITY \\ IN DEPLETED GAS FIELD
}

\section{INTRODUCTION}

The current stage of the resource base of oil and gas industry in Ukraine is characterized by deterioration of the structure and quality of the reserves. Most of the deposits, from which the main oil and gas production was received recently, entered a period of drop down production and final stage of the development. Some fields are on the verge of profitable hydrocarbons production (Borislavske, Ripnyanske, Skhidnytske, Kosmatske, Sahaydatske, Bytkiv-Babchynske (layers "Old Mine", "Dil") Shebelynske, West Khrestyshchenske, Efremivske, Melihivske, Kegychevske et al.). The proportion of high-oil reserves and hard-to-recover hydrocarbons reserves in low permeable layers and transition zones. Now the share of hard oil reserves equals over $70 \%$, gas - more than $15 \%$ of the total reserves. New deposits which have been involved into development over recent years are characterized by relatively small hydrocarbons reserves and cannot significantly affect the oil and gas production in Ukraine. Therefore, in the next decade, the main production will be insured from previously involved into development natural hydrocarbons fields that are at the various stages of development including not final stage.

The final stage of field development is characterized by a number of specific features: reservoir energy depletion, high water cut, low gas rates, the presence of micro- and makrotrapped gas and oil in watered layers, outbalance gas reserves and zones of varying degrees of permeability and drainage, which interact with each other, worsening sand face zone state, significant complications during the wells operation.

* Petroleum Engineering Institute, Ivano-Frankivsk National Technical University of Oil and Gas, Development and Operation of Oil and gas Fields Department, Ivano-Frankivsk, 15, Karpatska str., alexkondratr@gmail.com 
For many gas fields, namely Ukrainian, which are being developed in gas drive, there is a deviation of graphics rectilinear dependence of reduced average reservoir pressure from the theoretical straight line dependence. The reason for this may be the existence of imperfectly drained zones, zones with low-permeable reservoirs within the limits of the field. They include peripheral areas and separate areas in the field. These zones are being gradually involved in the development and are characterized by high reservoir pressure and gas flows from them into the recovery zone with production wells.

The final hydrocarbons recovery factor of the gas field development in the conditions of gas drive can be determined using the equation $[1,5]$ :

$$
\beta_{f}=1-\frac{P_{f} Z_{\text {init }}}{P_{\text {init }} Z_{f}}
$$

where:

$P_{\text {init }}, P_{f}$ - initial and final reservoir pressure correspondingly,

$Z_{\text {init }}, Z_{f}$ - gas compressibility factor at reservoir temperature and pressures $P_{\text {init }}$ and $P_{f}$ correspondingly.

According to the field data from developed gas domestic and foreign deposits final gas recovery factor in conditions of gas drive varies from $70 \%$ to $99 \%$ and an average equals $85-90 \%[1,5]$. That is, under the most favorable conditions of the geological structure and the field development on average from $10 \%$ to $15 \%$ of the initial gas reserves remain.

From the equation (1) it follows that the final gas recovery factor will be greater, than the lower will be the ratio of final to initial reservoir pressure and for a particular field the lower final reservoir pressure.

The increase of the final gas recovery factor of the gas field in the conditions of gas drive can be achieved by such methods $[1,5]$.

- Insuring uniform reservoir pressure reduction across the area and the productive section during the field development and the similar (near) final reservoir pressure values in all areas and layers of the deposits. This can be achieved by uniform placement of the production wells on the area with infill well pattern in low permeable zones of the reservoir, opening all gas-saturated layers in the wells, gas recovery intensification using horizontal and multilateral wells.

- Final reservoir pressure values minimization.

The lower is final reservoir pressure, the lower are pressure values at the inlet to the gas processing facility and pressure losses in the flow lines, wellbore and bottomhole zone of the wells.

Minimization of the pressure at the inlet to the gas processing facility can be achieved by boosting compressor station commissioning, using ejectors, gas supplying to local consumers and gas processing at the extraction site.

Thus, Khrestyshchensk compressor station reconstruction allowed by reducing pressure at its inlet from 1.2 to $0.6 \mathrm{MPa}$ to increase the current gas production from the 
Shebelynke field and Khrestyshchensk cluster of fields, to resume the low-pressured wells operation and increase the final gas recovery factor by reducing the final reservoir pressure [3]. In the unique by their reserves gas fields in the north of the Tyumen region it is foreseen to set up gas-chemical complexes and gas processing plants specialized in the production of granular polyethylene film production, liquefied gas and diesel fuel [4].

The reduction of the pressure loss in the wells flow lines can be achieved by preventing fluid accumulation in the humble areas and the hydrates formation.

The reduction of the pressure loss in the wellbore can be achieved by preventing hydrate formation, scale buildup, liquid and sand bridge formation on the bottomholes and homogeneous gas-liquid flow creation in the tubing.

The reduction of the pressure loss in the wells bottomhole zone can be achieved by using different methods of treatment (chemical, mechanical, physical) in order to clean porous media from pollution and increase its permeability compared to the natural value.

- Replacement of residual hydrocarbon gas from depleted deposits by non-hydrocarbon gases, liquids and mixtures thereof.

In [2, 6-9], the results of laboratory studies of the natural gas displacement from the reservoir models with carbon dioxide, nitrogen and flue gases were presented. In situ the conditions carbon dioxide density is from two to six times greater than the methane density, the carbon dioxide viscosity is also greater than the methane viscosity. Carbon dioxide has high dissolvability in formation water. All these features, according to the authors of [2], provide a relatively stable natural gas displacement with carbon dioxide and prevent gas quality decreasing by carbon dioxide solubility in water. Gas recovery ratio increase in the $\mathrm{CO}_{2}$ injection can reach $8-10 \% . \mathrm{CO}_{2}$ and natural gas mixing can be avoided by field development monitoring, while the diffusivity of carbon dioxide less than $1 \cdot 10^{-6} \mathrm{~m}^{2} / \mathrm{s}$ the diffusion impact on gas mixing and $\mathrm{CO}_{2}$ dispersion cannot be taken into account [2].

According to the experimental results [6-9] carbon dioxide has better displacement properties compared with nitrogen, and high $\mathrm{CO}_{2}$ solubility in water delays the time of its breakthrough to wells.

\section{RESEARCH METHODS}

Hypothetical deposit with the central highly permeable (active) zone together with production wells and peripheral low permeable (passive) zone, without production wells, was considered.

Gas reserves in the active zone equal $30 \cdot 10^{9} \mathrm{~m}^{3}$, in the passive zone $-10 \cdot 10^{9} \mathrm{~m}^{3}$. The reservoirs permeability coefficient in the active zone is $0.5 \mathrm{D}$ in the passive zone $0,1 \cdot 10^{-3} ; 0,5 \cdot 10^{-3} ; 1 \cdot 10^{-3} ; 5 \cdot 10^{-3} ; 10 \cdot 10^{-3} ; 15 \cdot 10^{-3} \mathrm{D}$. For each zone the material balance equations for gas drive are recorded, considering the amount of gas flowing from or into 
the zone. Between zones there is a single-phase real gas flowing according to the Darcy law. Initial reservoir pressure, reservoir temperature and gas composition in both areas are the same. Pore volume in the active and passive zones during the field development remains unchanged. Let us assume gas field as a circle. The radius of the active zone is denoted as $R_{a}$, outer deposits contour radius (passive zone) $-R_{p}$ (Fig. 1).

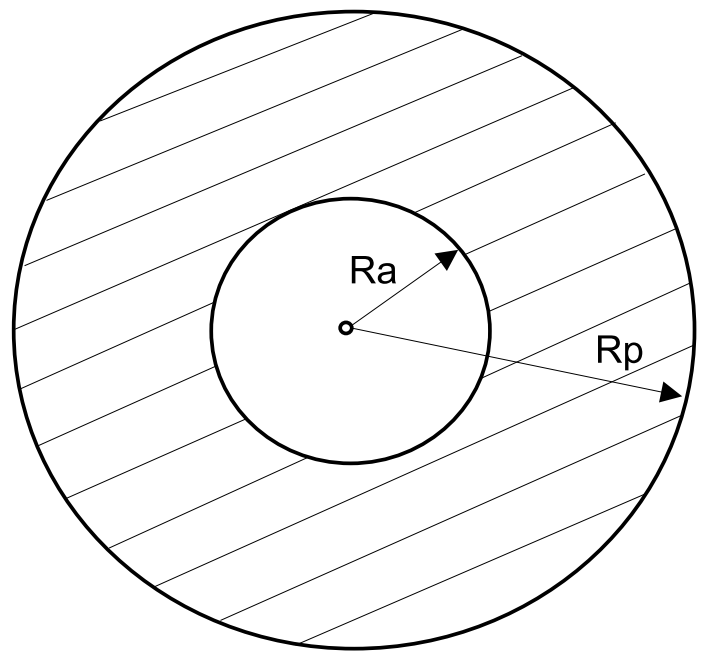

Fig. 1. Gas field approximation of active and passive zones for conducting the study of gas cross-flow process between them

The material balance equation for active and passive zones of the field was set as the basis for calculation:

$$
\begin{gathered}
\frac{\alpha_{\text {init.a } . a} \Omega_{\text {init. } .} P_{\text {init }} T_{\text {st }}}{Z_{\text {init }} P_{\text {atm }} T_{\text {res }}}=\frac{\alpha_{\text {init. } .} \Omega_{\text {init.a }} \tilde{P}_{\text {res.a }}(t) T_{\text {st }}}{Z\left(\tilde{P}_{\text {res.a }}\right) P_{\text {atm }} T_{\text {res }}}+Q_{\text {cum }}(t)-Q_{f}(t) \\
\frac{\alpha_{\text {init. } p} \Omega_{\text {init. } p} P_{\text {init }} T_{\text {st }}}{Z_{\text {init }} P_{\text {atm }} T_{\text {res }}}=\frac{\alpha_{\text {init. } p} \Omega_{\text {init. } p} \tilde{P}_{\text {res. } p}(t) T_{\text {st }}}{Z\left(\tilde{P}_{\text {res. } p}\right) P_{\text {atm }} T_{\text {res }}}+Q_{f}(t)
\end{gathered}
$$

where:

$$
\begin{gathered}
Q_{f}(t)=Q_{f}\left(t_{n-1}\right)+\frac{\left[q_{f}\left(t_{n-1}\right)+q_{f}(t)\right]}{2} \Delta t \\
q_{f}(t)=\frac{\pi \kappa_{p} h_{p} T_{s t}\left[\tilde{P}_{\text {res.p }}^{2}(t)-\tilde{P}_{\text {res. }}^{2}(t)\right]}{\mu_{a v \cdot p} Z_{a v \cdot p} P_{\text {atm }} T_{r e s} \ln \frac{R_{p}}{R_{a}}}
\end{gathered}
$$


where:

$$
\begin{aligned}
& P_{\text {init }} \text { - initial reservoir pressure, } \\
& T_{\text {res }}, T_{s t}-\text { reservoir and standard temperature accordingly, } \\
& \Omega_{\text {init.a }}, \Omega_{\text {init.p }}-\text { initial pore volume in the active and passive zones } \\
& \text { accordingly, } \\
& \tilde{P}_{\text {res.a }}(t), \tilde{P}_{\text {res.p }}(t) \text { - initial average reservoir pressure in active and passive } \\
& \text { zones accordingly, } \\
& \alpha_{\text {init.a }}, \alpha_{\text {init.p }}-\text { initial gas saturation in active and passive zones accord- } \\
& \text { ingly, } \\
& Z_{\text {init }}, Z\left(\tilde{P}_{\text {res.a }}\right), Z\left(\tilde{P}_{\text {res.p }}\right) \text { - gas compressibility coefficient at the reservoir tempera- } \\
& \text { ture and pressures } P_{\text {init }}, \tilde{P}_{\text {res.a }}(t), \tilde{P}_{\text {res. }}(t) \text { accordingly, } \\
& Q_{\text {cum }}(t) \text { - cumulative gas production from the field, } \\
& Q_{f}(t) \text { - cumulative amount of gas, which cross-flows from } \\
& \text { passive to active zone, } \\
& q_{f}(t) \text { - current gas rate, which cross-flows from passive to active } \\
& \text { zone, } \\
& \kappa_{p}-\text { average value of reservoir permeability of the passive } \\
& \text { zone, } \\
& h_{p} \text { - average value of effective reservoir thickness of the } \\
& Z_{\text {av.p }} \text { - average current value of the gas compressibility factor } \\
& \text { in passive zone, } \\
& \Delta t \text { - time period (calculation step). }
\end{aligned}
$$

\section{RESULTS}

The results of the studies confirm the assumption about gas cross-flow between zones with different permeability and its impact on the dependence of the reduced average reservoir pressure upon cumulative gas production (Fig. 2). The degree of interaction between the central zone and peripheral zones depends on the permeability of the passive zone. For passive zone permeability value $0,1 \cdot 10^{-3} \mathrm{D}$ the dependence of the reduced average reservoir pressure on cumulative gas production $\tilde{P}_{\text {res }}(t) / Z\left(\tilde{P}_{\text {res }}\right)=f\left[Q_{\text {cum }}(t)\right]$ for the active zone is similar to the straight line which corresponds to the initial gas reserves in this zone. This testifies to minor gas cross-flows from the passive to the active zone. In the passive zone the reservoir pressure decreases from an initial value of $36 \mathrm{MPa}$ to $31.67 \mathrm{MPa}$ at the time of field development completion (31 year) (see. Fig. 2a). With the passive zone permeability increasing the dependence $\tilde{P}_{r e s}(t) / Z\left(\tilde{P}_{\text {res }}\right)=f\left[Q_{\text {cum }}(t)\right]$ for the active zone gradually deviates from a straight line and the horizontal axis, and for the passive zone it decreases rapidly towards the x-axis (see. Fig. 2b). 
a)

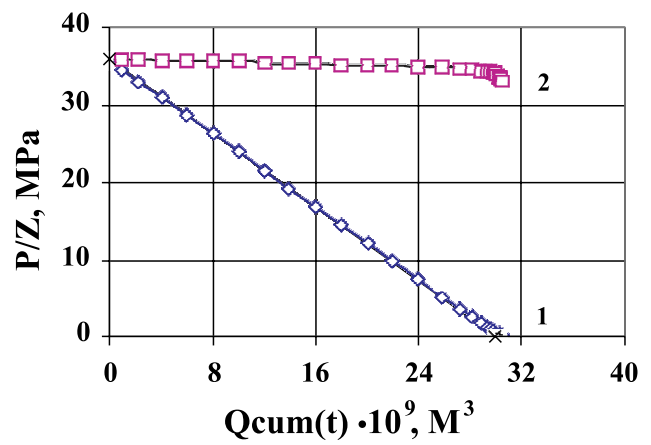

b)

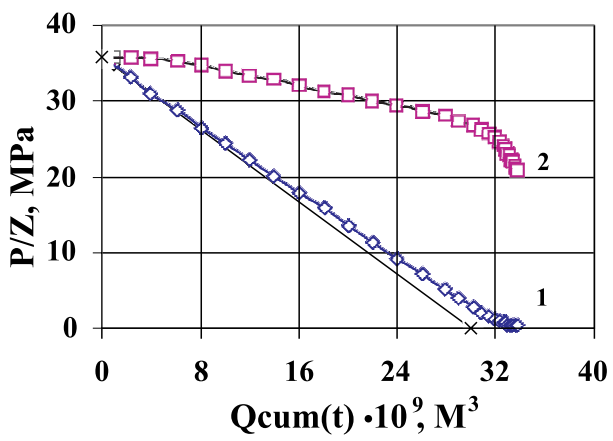

Fig. 2. Graphical dependencies of the reduced average reservoir pressure on cumulative gas production in the field for active (1) and passive (2) zones with passive zone permeability of $0,1 \cdot 10^{-3} \mathrm{D}(\mathrm{a})$ and $1 \cdot 10^{-3} \mathrm{D}(\mathrm{b})$

At the final stage of field development some flattening of this relationship for the active zone has been observed. Thus, the deviation of the dependence $\tilde{P}_{r e s}(t) / Z\left(\tilde{P}_{\text {res }}\right)=f\left[Q_{\text {cum }}(t)\right]$ from the theoretical straight line for the gas field in gas drive may be caused due to the presence in the field the zones with different permeability and in-situ gas cross-flows between them.

During the field development the reservoir pressure difference between zones gradually increases over time, reaching a maximum and then decreases (Fig. 3a). The maximum pressure differential between zones is so greater, so lower is the permeability of the passive zone. With passive zone permeability increase from $0,1 \cdot 10^{-3}$ to $0,5 \cdot 10^{-3} \mathrm{D}$ the maximum pressure differential between zones is achieved earlier, and with the further passive zone permeability increase - later. The gas flow rate between zones gradually increases over time, reaching a maximum and then decreases (Fig. 3b). With passive zone permeability increase maximum gas flow rate between zones is achieved earlier and its absolute value increases.

Cyclic and periodic field development is referred to the potential ways of gas extraction from the passive zone. After lowering the reservoir pressure in the active zone to a certain value the wells operation is halted for some period of time for the gas cross-flow from the passive zone into the active one, and then they are recommissioned. This process is repeated periodically. In order to assess the effectiveness of cyclic, periodic field development the researches were conducted, in which after 31-year of the gas field development gas production was stopped and pressures changes in the active and passive zones were determined over the time.

The calculation results shows that for the passive zone permeability of $0,1 \cdot 10^{-3} \mathrm{D}$ the process of gas cross-flow from the passive zone and pressure restoration in the active zone are very slow and may last for decades. In the 20th year since the beginning of the field downtime the reservoir pressure in the passive zone decreased from 31.67 to $28.3 \mathrm{MPa}$ 
and in the active zone it increased from 0.28 to $0.87 \mathrm{MPa}$ (Fig. 4a). For passive zone permeability of $1 \cdot 10^{-3} \mathrm{D}$ after 10 years of field downtime reservoir pressure in the passive zone decreased from 15.42 to $13.98 \mathrm{MPa}$ and the pressure in the active zone increased from 0.46 to $1.44 \mathrm{MPa}$ (Fig. $4 \mathrm{~b}$ ).

a)

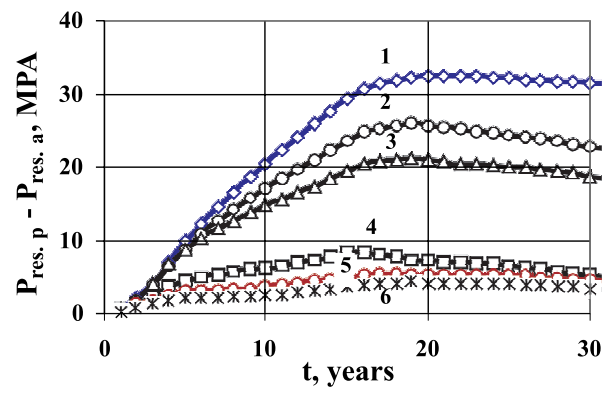

b)

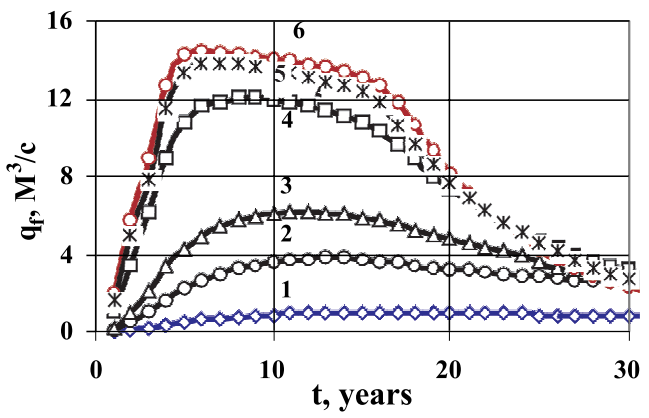

$$
1-0,1 \cdot 10^{-3} ; 2-0,5 \cdot 10^{-3} ; 3-1 \cdot 10^{-3} ; 4-5 \cdot 10^{-3} ; 5-10 \cdot 10^{-3} ; 6-15 \cdot 10^{-3} \mathrm{D}
$$

Fig. 3. Pressure differential dynamics between passive and active zones (a) and gas cross-flow rate between zones (b), for different values of the passive zone permeability

a)

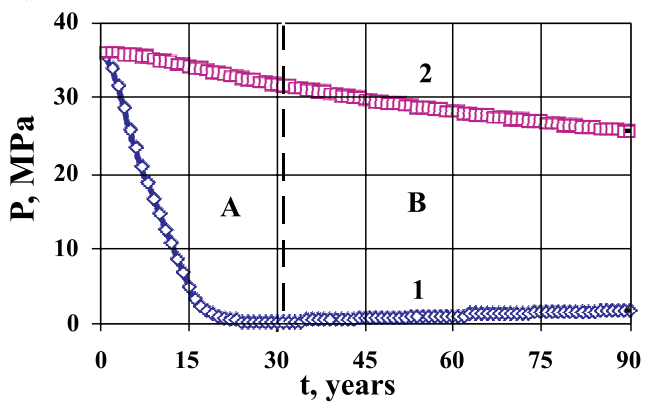

b)

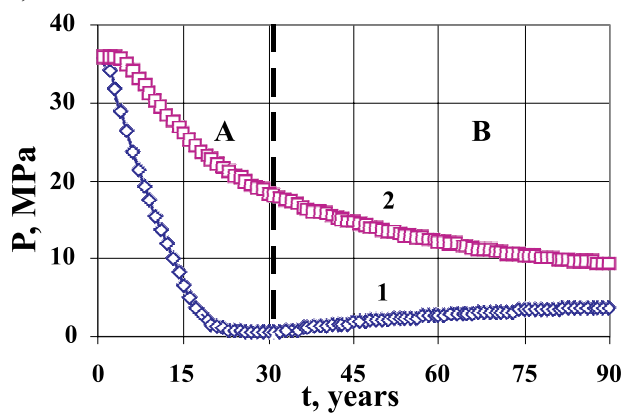

Fig. 4. Dynamics of the reservoir pressure in the active (1) and passive (2) zones during the process of development (A) and after the field downtime (B) for the value of passive zone permeability of $0,1 \cdot 10^{-3} \mathrm{D}(\mathrm{a})$ and $1 \cdot 10^{-3} \mathrm{D}(\mathrm{b})$

\section{RESULTS DISCUSSION}

Presented results indicate that with relatively high permeability of the passive zone cyclic, periodic development of the depleted gas field is completely possible. This allows increasing the final gas recovery factor by gas cross-flowing from the passive to the active zone during field downtime. For the low value of passive zone permeability gas cross-flow between zones is very slow and can last for decades. Thus, at the permeability of the passive 
zone of $0,1 \cdot 10^{-3} \mathrm{D}$ after the period of the field downtime from 31-year to 90 -year (after 59 years) pressure in the passive zone decreased from 31.67 to $25.6 \mathrm{MPa}$, and pressure in the active zone increased from 0.29 to $1.81 \mathrm{MPa}$. That is why in case of the low permeability of the passive zone the methods of gas production intensification in the low permeable zones, including unconventional fields, must be used. From this perspective, a promising technological solution is to drill injection wells in the area (zones) with outbalance gas reserves and non-hydrocarbon gases injection into them in order to displace residual gas in the extraction area with production wells.

\section{CONCLUSIONS}

According to the results of conducted researches the mathematical model of interaction on the gas field reservoir areas with different degrees of permeability and drainage as a result of gas cross-flow between them was proposed. Applying a suggested mathematical model the impact of interaction of different permeable zones in the macroheterogeneous field on the shape of the dependence of reduced average reservoir pressure from cumulative gas production was estimated and the opportunity to identify the presence of outbalance reserves in the field noninvolved into the development was found out. Layers with outbalance gas reserves can be considered as the perspective zones for their development.

\section{REFERENCES}

[1] Abasov M., Abbasov Z., Aliyarov R., Jalalov G., Kondrushrin Y., Hamidov N., Krutikh L., Mustafayev R., Rzayeva V., Feyzullaev Kh.: Geological and Development Features of Marine Deep Gas-Condensate Fields in Azerbayjan. Offshore Technology Conference, 4/30/2001, Houston, Texas.

[2] Al-Hashami A., Ren S.R., Tohidi B.: Injection for Enhanced Gas Recovery and GeoStorage: Reservoir Simulation and Economics. SPE Europec/EAGE Annual Conference, 13-16 June 2005, Madrid, Spain.

[3] Fyk I.M., Rybchych I.J.: Naukovi osnovy pidvyshhennya efektyvnosti rozrobky hazokondensatnyx rodovyshh Ukrayiny. Nauka ta innovaciyi, 1, No. 5, 2005, 40-49.

[4] Levinzon I.: Gazovaya kladovaya Rossii. Ekonomika Rossii: XXI vek, No. 14, 2004, 7 p.

[5] Shmyhlya P.T.: Razrabotka hazovyx y hazokondensatnux mestorozhdenyj. Nedra, 1967, 258 p.

[6] Sim S.S.K., Turta A.T., Singhal A.K., Hawkins B.F.: Enhanced Gas Recovery: Factors Affecting Gas-Gas Displacement Efficiency. PAPER 2008-145, Canadian International Petroleum Conference, 17-19 June, Calgary, Alberta 2008.

[7] Sim S.S.K., Turta A.T., Singhal A.K., Hawkins B.F.: Enhanced Gas Recovery: Effect of Reservoir Heterogeneity on Gas-Gas Displacement. PAPER 2009-023, Canadian International Petroleum Conference, 16-18 June, Calgary, Alberta 2009. 
[8] Sim S.S.K., Turta A.T., Singhal A.K., Hawkins B.F.: Enhanced Gas Recovery: Factors Affecting Gas-Gas Displacement Efficiency. PETSOC-09-08-49-P, 9th Canadian International Petroleum Conference (the 59th Annual Technical Meeting of the Petroleum Society), June 17-19, 2008, in Calgary, Alberta.

[9] Sim S.S.K., Turta A.T., Singhal A.K., Hawkins B.F.: Basic Investigations on Enhanced Gas Recovery by Gas-Gas Displacement. PAPER 2007-124, Journal of Canadian Petroleum Technology, vol. 47, Issue 10, 2008.

[10] Sim S.S.K., Brunelle P., Turta A.T., Singhal A.K.: Enhanced Gas Recovery and $\mathrm{CO}_{2}$ Sequestration by Injection of Exhaust Gases from Combustion of Bitumen. SPE 113468, SPE Symposium on Improved Oil Recovery, 20-23 April 2008, Tulsa, Oklahoma, USA.

[11] Zakirov S.N., Aliev B.A.: Povyshenie kondensatootdachi plasta. Obzornaya informatsiya. Seriya: Razrabotka gazovykh i gazokondensatnykh mestorozhdeniy - M.: VNIIJegazprom, vyp. 4, 1985, 46 p. 